\title{
The hypertriglyceridemic-waist phenotype and the risk of coronary artery disease: results from the EPIC-Norfolk Prospective Population Study
}

\author{
Benoit J. Arsenault PhD, Isabelle Lemieux PhD, Jean-Pierre Després PhD, \\ Nicholas J. Wareham MBBS PhD, John J.P. Kastelein MD PhD, Kay-Tee Khaw MBBChir, \\ S. Matthijs Boekholdt MD PhD
}

Previously published at www.cmaj.ca

\section{ABSTRACT}

Background: Screening for increased waist circumference and hypertriglyceridemia (the hypertriglyceridemic-waist phenotype) has been proposed as an inexpensive approach to identify patients with excess intra-abdominal adiposity and associated metabolic abnormalities. We examined the relationship between the hypertriglyceridemic-waist phenotype to the risk of coronary artery disease in apparently healthy individuals.

Methods: A total of 21787 participants aged 45-79 years were followed for a mean of 9.8 (standard deviation 1.7) years. Coronary artery disease developed in 2109 of them during follow-up. The hypertriglyceridemic-waist phenotype was defined as a waist circumference of $90 \mathrm{~cm}$ or more and a triglyceride level of $2.0 \mathrm{mmol} / \mathrm{L}$ or more in men, and a waist circumference of $85 \mathrm{~cm}$ or more and a triglyceride level of $1.5 \mathrm{mmol} / \mathrm{L}$ or more in women.

Results: Compared with participants who had a waist circumference and triglyceride level below the threshold, those with the hypertriglyceridemic-waist phenotype had higher blood pressure indices, higher levels of apolipoprotein B and C-reactive protein, lower levels of high-density lipoprotein cholesterol and apolipoprotein A-I, and smaller low-density lipoprotein particles. Among men, those with the hypertriglyceridemic-waist phenotype had an unadjusted hazard ratio for future coronary artery disease of 2.40 (95\% confidence interval $[\mathrm{Cl}] 2.02-2.87$ ) compared with men who did not have the phenotype. Women with the phenotype had an unadjusted hazard ratio of 3.84 (95\% Cl 3.20-4.62) compared with women who did not have the phenotype.

Interpretation: Among participants from a European cohort representative of a contemporary Western population, the hypertriglyceridemic-waist phenotype was associated with a deteriorated cardiometabolic risk profile and an increased risk for coronary artery disease. lthough obesity is a health hazard, not every obese person has the expected metabolic abnormalities associated with excess body fat. ${ }^{1,2}$ Epidemiologic and metabolic studies have shown that the metabolic complications of overweight and obesity are more related to the local- ization rather than to the amount of total body fat. ${ }^{3,4}$ Imaging studies using techniques such as computed tomography or magnetic resonance imaging have shown that, among equally obese individuals, those with an excess of intra-abdominal or visceral adipose tissue have metabolic abnormalities and are at increased risk of coronary artery disease and type 2 diabetes. ${ }^{5-7}$

The systematic measurement of waist circumference has been proposed as a crude anthropometric correlate of intraabdominal adiposity. ${ }^{8}$ However, because waist circumference cannot fully discriminate intra-abdominal from subcutaneous abdominal adiposity, we previously suggested that the presence of elevated triglyceride levels could be used as a marker of "dysfunctional" adipose tissue, intra-abdominal obesity and associated metabolic abnormalities in people with an increased waistline..$^{9-11}$ What we had initially described as the hypertriglyceridemic-waist phenotype - the combination of an increased waist circumference and hypertriglyceridemia could be a useful and inexpensive screening tool to identify people at increased risk of coronary artery disease and type 2 diabetes. ${ }^{12-14}$ In this article, we report on the performance of the hypertriglyceridemic-waist phenotype as a screening tool among participants enrolled in the European Prospective Investigation into Cancer and Nutrition (EPIC)-Norfolk study.

\section{Methods}

\section{Study design}

The EPIC-Norfolk study is a population-based study involving 25668 men and women aged 45-79 years in Norfolk, United Kingdom, who completed a baseline questionnaire and attended a clinic visit. ${ }^{15}$ Participants were recruited from

From the Centre de recherche de I'Institut universitaire de cardiologie et de pneumologie de Québec (Arsenault, Lemieux, Després), Québec, Que.; the Departments of Vascular Medicine (Arsenault, Boekholdt, Kastelein) and Cardiology (Boekholdt), Academic Medical Center, University of Amsterdam, Amsterdam, the Netherlands; the Division of Kinesiology, Department of Social and Preventive Medicine (Després), Université Laval, Laval, Que.; the Medical Research Council Epidemiology Unit (Wareham), Cambridge, United Kingdom; and the Department of Public Health and Primary Care, Institute of Public Health (Khaw), University of Cambridge, Cambridge, United Kingdom

CMAJ 2010. DOI:10.1503/cmaj.091276 
age-sex registers of general practices in Norfolk as part of the 10-country collaborative EPIC study designed to investigate diet and other determinants of cancer. Additional data were obtained in the EPIC-Norfolk study to enable the assessment of determinants of other diseases. The study cohort was similar to samples of the UK population in many characteristics, including anthropometry, blood pressure and lipid levels, but it had a lower proportion of smokers.

The design and methods of the study have been described in detail previously. ${ }^{15}$ In brief, eligible participants were recruited by mail. At the baseline survey, conducted between 1993 and 1997, participants completed a detailed health and lifestyle questionnaire. We measured their waist circumference (at the smallest circumference between the ribs and iliac crest). Blood samples were analyzed for various markers (for methods of the blood analyses, see Appendix 1, available at www.cmaj.ca/cgi/content/full/cmaj.091276/DC1).

Mortality data were obtained from the UK Office of National Statistics. Death was considered to be due to coronary artery disease if the underlying cause was assigned International Classification of Diseases 9th revision (ICD-9) codes 410 to 414 (unstable angina, stable angina or myocardial infarction). Previous validation studies involving our cohort indicated high specificity for such case ascertainment. ${ }^{16}$

In addition, we reviewed data on hospital admissions by linking participants' unique National Health Service numbers with data from ENCORE (the East Norfolk Health Authority database), which identifies all hospital contacts throughout England and Wales for Norfolk residents. Participants were identified as having coronary artery disease if they were admitted to hospital because of coronary artery disease.

\begin{tabular}{|c|c|c|}
\hline Characteristic & $\begin{array}{c}\text { Men } \\
n=9506\end{array}$ & $\begin{array}{l}\text { Women } \\
n=12281\end{array}$ \\
\hline Age, yr, mean (SD) & $58.7(9.3)$ & $58.1(9.3)$ \\
\hline Body mass index, mean (SD) & $26.4(3.2)$ & $26.1(4.2)$ \\
\hline Waist circumference, $\mathrm{cm}$, mean (SD) & $95.3(9.6)$ & $81.7(10.7)$ \\
\hline Waist:hip ratio, mean (SD) & $0.93(0.06)$ & $0.79(0.06)$ \\
\hline \multicolumn{3}{|l|}{ Smoking, no. (\%) } \\
\hline Current & $1138(12.0)$ & $1386(11.3)$ \\
\hline Past & $5087(53.5)$ & $3906(31.8)$ \\
\hline Never & $3281(34.5)$ & $6989(56.9)$ \\
\hline History of diabetes, no. (\%) & $233(2.5)$ & 154 (1.3) \\
\hline $\begin{array}{l}\text { Systolic blood pressure, } \mathrm{mm} \mathrm{Hg} \text {, } \\
\text { mean (SD) }\end{array}$ & $137(17)$ & $133(19)$ \\
\hline $\begin{array}{l}\text { Diastolic blood pressure, } \mathrm{mm} \mathrm{Hg} \text {, } \\
\text { mean (SD) }\end{array}$ & $84(11)$ & $80(11)$ \\
\hline Total cholesterol, mmol/L, mean (SD) & $6.0(1.1)$ & $6.3(1.2)$ \\
\hline LDL cholesterol, mmol/L, mean (SD) & $3.0(1.0)$ & $4.0(1.1)$ \\
\hline HDL cholesterol, $\mathrm{mmol} / \mathrm{L}$, mean (SD) & $1.2(0.3)$ & $1.6(0.4)$ \\
\hline Triglycerides, mmol/L, median (IQR) & $1.7(1.2-2.4)$ & $1.4(1.0-1.9)$ \\
\hline
\end{tabular}

Note: $\mathrm{HDL}=$ high-density lipoprotein, $\mathrm{IQR}=$ interquartile range, $\mathrm{LDL}=$ lowdensity lipoprotein, $\mathrm{SD}=$ standard deviation.
We considered a participant to have diabetes mellitus at baseline if he or she reported using diabetes medication, brought diabetes medication to the baseline health check, indicated modifying his or her diet in the past year because of diabetes or reported adhering to a diabetic diet.

The Ethics Committee of the Norwich District Health Authority approved the study design. All of the participants gave signed informed consent.

\section{Study participants}

We examined the association between the hypertriglyceridemic-waist phenotype and risk of coronary artery disease in the entire cohort $(n=21758)$. The extended set of risk markers that was used to analyze the relationship between the phenotype and characteristics of the metabolic syndrome was available only in a nested case-control sample within the cohort $(n=2840)$. This sample has been previously described. ${ }^{17,18}$ We performed survival analyses in the entire cohort. We report results for participants who did not have coronary artery disease at baseline and were followed up to March 2007.

\section{Hypertriglyceridemic-waist phenotype}

For men, the phenotype was defined as a waist circumference of $90 \mathrm{~cm}$ or more and a triglyceride level of $2.0 \mathrm{mmol} / \mathrm{L}$ or more. ${ }^{10,19}$ For women, the cut-off values for the phenotype were $85 \mathrm{~cm}$ for waist circumference and $1.5 \mathrm{mmol} / \mathrm{L}$ for triglyceride levels. ${ }^{20}$ In both men and women, these cut-off values correspond to the value with the highest sum of sensitivity and (1-specificity) rounded up to the closest centimetre and to the highest decimal.

\section{Statistical analysis}

We used Cox regression analysis to calculate hazard ratios and corresponding $95 \%$ confidence intervals for the risk of coronary artery disease. The interaction term between waist circumference and triglyceride levels in predicting the risk of coronary artery disease was also tested. We calculated hazard ratios for coronary artery disease in each category before and after adjusting for the individual risk factors used in the Framingham risk score. Kaplan-Meier survival curves were computed separately for men and women, who were classified into four groups according to waist circumference and triglyceride levels. We assessed differences between curves using the log-rank test. A $p$ value of less than 0.05 was considered to be statistically significant.

\section{Results}

Complete data on traditional cardiovascular risk factors were available for 21787 participants (9506 men and 12281 women) who did not have coronary artery disease at baseline. The mean follow-up period was 9.8 (standard deviation 1.7) years. Coronary artery disease developed during the followup period in 2109 participants (1295 men and 814 women). Baseline characteristics of the entire study cohort are presented in Table 1.

Baseline anthropometric and metabolic variables measured in the nested case-control sample of 2840 participants classi- 
fied on the basis of their waist circumference and triglyceride levels are shown in Table 2. Among both men and women, participants with an increased waist circumference and elevated triglyceride levels were older, had a higher mean body mass index and higher mean systolic and diastolic blood pressures than participants with lower waist circumference and triglyceride levels. They also had the most atherogenic metabolic risk profile, with the highest concentrations of total cholesterol, low-density lipoprotein cholesterol, C-reactive protein and apolipoprotein B. Participants with the hyper- triglyceridemic-waist phenotype also had lower high-density lipoprotein cholesterol and apolipoprotein A-I levels, and smaller low-density lipoprotein particles.

Table 3 displays hazard ratios for the risk of coronary artery disease before and after adjustment for traditional risk factors, including age, total cholesterol level, high-density lipoprotein cholesterol level, systolic blood pressure, smoking and presence of diabetes. Among both men and women, an increase in waist circumference (even without elevated triglyceride levels) and elevated triglyceride levels (even

Table 2: Baseline characteristics of 2840 participants for whom extensive metabolic markers were available, by waist circumference and triglyceride levels*

\begin{tabular}{|c|c|c|c|c|}
\hline Characteristict & $\begin{array}{c}\text { Normal waist } \\
\text { circumference / } \\
\text { normal triglyceride } \\
\text { levels }\end{array}$ & $\begin{array}{c}\text { Normal waist } \\
\text { circumference / } \\
\text { elevated triglyceride } \\
\text { levels }\end{array}$ & $\begin{array}{c}\text { Increased waist } \\
\text { circumference / } \\
\text { normal triglyceride } \\
\text { levels }\end{array}$ & $\begin{array}{c}\text { Increased waist } \\
\text { circumference / } \\
\text { elevated triglyceride } \\
\text { levels }\end{array}$ \\
\hline Men & $n=340$ & $n=87$ & $n=803$ & $n=558$ \\
\hline Age, yr & $63.6(8.4)$ & $61.7(8.7)$ & $65.2(7.9)$ & $64.2(7.9)$ \\
\hline Body mass index & $23.4(1.9)$ & $24.0(1.7)$ & $27.2(2.7)$ & $28.2(3.2)$ \\
\hline Systolic blood pressure, $\mathrm{mm} \mathrm{Hg}$ & $137.2(18.0)$ & $136.8(16.2)$ & $141.2(18.6)$ & $143.6(17.2)$ \\
\hline Diastolic blood pressure, $\mathrm{mm} \mathrm{Hg}$ & $81.9(10.8)$ & $83.8(10.5)$ & $85.1(11.9)$ & $87.3(10.8)$ \\
\hline Total cholesterol, $\mathrm{mmol} / \mathrm{L}$ & $5.8(1.0)$ & $6.7(1.2)$ & $5.9(1.0)$ & $6.5(1.1)$ \\
\hline LDL cholesterol, mmol/L & $3.9(0.0)$ & $4.3(1.2)$ & $4.0(0.9)$ & $4.1(1.0)$ \\
\hline HDL cholesterol, $\mathrm{mmol} / \mathrm{L}$ & $1.4(0.4)$ & $1.2(0.3)$ & $1.3(0.3)$ & $1.1(0.3)$ \\
\hline LDL peak particle size, $\AA$ & 261.0 & $258.2(5.1)$ & 260.5 (4.2) & 256.9 (4.4) \\
\hline Apolipoprotein A-I, g/L & $1.60(0.27)$ & $1.52(0.24)$ & $1.53(0.25)$ & $1.45(0.23)$ \\
\hline Apolipoprotein B, g/L & $1.19(0.25)$ & $1.42(0.34)$ & $1.24(0.28)$ & $1.44(0.28)$ \\
\hline $\mathrm{HbA}_{1 c^{\prime}} \%$ & $5.4(0.8)$ & $5.7(1.2)$ & $5.5(0.8)$ & $5.7(1.2)$ \\
\hline Women & $n=353$ & $n=253$ & $n=154$ & $n=292$ \\
\hline Age, yr & $65.6(7.7)$ & $66.5(6.8)$ & $66.9(7.3)$ & $68.0(6.6)$ \\
\hline Body mass index & $23.9(2.4)$ & $24.7(2.6)$ & $29.4(4.0)$ & 29.9 (3.9) \\
\hline Waist circumference, $\mathrm{cm}$ & $76.2(5.3)$ & $78.2(4.9)$ & $92.9(7.0)$ & $94.8(8.4)$ \\
\hline Systolic blood pressure, $\mathrm{mm} \mathrm{Hg}$ & $134.1(17.9)$ & $140.9(17.5)$ & $138.9(19.2)$ & $146.0(18.5)$ \\
\hline C-reactive protein, mg/L & $2.7(6.0)$ & $2.9(4.0)$ & $5.4(8.0)$ & $5.8(8.6)$ \\
\hline LDL peak particle size, $\AA$ & $262.8(4.3)$ & 260.7 (4.3) & 262.8 (4.4) & $259.3(4.6)$ \\
\hline Apolipoprotein A-I, g/L & $1.82(0.33)$ & $1.77(0.30)$ & $1.74(0.27)$ & $1.68(0.28)$ \\
\hline Apolipoprotein B, g/L & $1.19(0.27)$ & $1.45(0.33)$ & $1.19(0.25)$ & $1.48(0.31)$ \\
\hline $\mathrm{HbA}_{1 c^{\prime}} \%$ & $5.3(0.7)$ & $5.6(0.8)$ & $5.5(0.5)$ & $5.8(1.3)$ \\
\hline
\end{tabular}

Note: $\mathrm{HbA}_{1 \mathrm{c}}=$ glycated hemoglobin $\mathrm{A}_{1, r} \mathrm{HDL}=$ high-density lipoprotein, $\mathrm{LDL}=$ low-density lipoprotein, $\mathrm{SD}=\mathrm{standard}$ deviation.

*A normal waist circumference was less than $90 \mathrm{~cm}$ for men and less than $85 \mathrm{~cm}$ for women. Normal triglyceride levels were less than $2.0 \mathrm{mmol} / \mathrm{L}$ for men and less than $1.5 \mathrm{mmol} / \mathrm{L}$ for women.

tValues are given as means and standard deviations. 
without an increase in waist circumference) increased the risk of coronary artery disease. However, the combination of increased waist circumference and elevated triglyceride levels (the hypertriglyceridemic-waist phenotype) was associated with the highest risk among both men and women. This relationship remained significant after adjustment for traditional risk factors for coronary artery disease.

The Kaplan-Meier survival curves for participants stratified into four groups on the basis of waist circumference and triglyceride levels are shown in Figure 1. Among both men and women, the probability of survival without coronary artery disease was lower among participants with either an elevated triglyceride level or an increased waist circumference than among those with both normal waist circumference and triglyceride levels. However, men and women who had both an increased waist circumference and hypertriglyceridemia had the worst disease-free survival curves $(p<0.001$ for both sexes).

Figure 2 shows the risk of coronary artery disease according to Framingham risk scores and the hypertriglyceridemic-waist phenotype. Among men and women with the lowest Framingham risk score, those with the phenotype were at greater risk of coronary artery disease than those without the phenotype.

\section{Interpretation}

Our study provides evidence from a large European cohort that the hypertriglyceridemic-waist phenotype is a simple and inexpensive marker to help identify patients with intraabdominal obesity who have a deteriorated cardiometabolic risk profile and are thus at increased risk of coronary artery disease. An additional advantage is that the phenotype can be determined easily, without additional and expensive testing. Plasma triglyceride levels are available from any standard lipid profile obtained in clinical practice, and waist circumference can be measured at no cost.

Few prospective studies have evaluated the association between the hypertriglyceridemic-waist phenotype and risk of coronary artery disease in large cohorts. Czernichow and colleagues reported that the presence of the phenotype predicted the incidence of cardiovascular events in a French cohort of 3430 men. ${ }^{21}$ Tanko and colleagues reported evidence that the combination of increased waist circumference and elevated triglyceride levels was associated with aortic calcification among postmenopausal women. ${ }^{22}$ They also reported that, among participants with and without the metabolic syndrome, a further stratification on the basis of waist circumference and triglyceride levels significantly increased the risk of aortic calcification.

The concept of the hypertriglyceridemic-waist phenotype was introduced by Lemieux and colleagues..$^{10}$ They suggested that this simple phenotype could be a useful marker of a triad of metabolic abnormalities (hyperinsulinemia, hyperapolipoprotein B and small, dense low-density lipoprotein particles), whose presence is a strong risk factor for coronary artery disease. ${ }^{10,23}$ The metabolic risk profile of the subsample in our study (Table 2) shows that the presence of the hypertriglyceridemic-waist phenotype was predictive of a deteriorated cardiometabolic risk profile predictive of an increased risk for type 2 diabetes and coronary artery disease.

Waist circumference is a simple and inexpensive marker of abdominal adiposity, but not all people with an increased waistline are viscerally obese and at increased risk of coronary artery disease. Therefore, elevated plasma triglyceride levels have

Table 3: Risk of coronary artery disease among 21787 participants before and after adjustment for traditional risk factors, by waist circumference and triglyceride levels

\begin{tabular}{|c|c|c|c|c|c|}
\hline Variable & $\begin{array}{c}\text { Normal waist } \\
\text { circumference / } \\
\text { normal triglyceride } \\
\text { levels }\end{array}$ & $\begin{array}{c}\text { Normal waist } \\
\text { circumference / } \\
\text { elevated triglyceride } \\
\text { levels }\end{array}$ & $\begin{array}{c}\text { Increased waist } \\
\text { circumference / } \\
\text { normal triglyceride } \\
\text { levels }\end{array}$ & $\begin{array}{c}\text { Increased waist } \\
\text { circumference / } \\
\text { elevated triglyceride } \\
\text { levels }\end{array}$ & $\begin{array}{l}p \text { value for } \\
\text { interaction* }\end{array}$ \\
\hline \multicolumn{6}{|l|}{ Men } \\
\hline Follow-up, no. of person-years & 22910 & 6768 & 40619 & 32130 & \\
\hline No. of events & 162 & 75 & 516 & 542 & \\
\hline Unadjusted & 1.00 (ref) & $1.57(1.20-2.08) \ddagger$ & $1.81(1.52-2.08) \ddagger$ & $2.40(2.02-2.87) \S$ & 0.25 \\
\hline Adjusted $\dagger$ & 1.00 (ref) & $1.12(0.84-1.48)$ & $1.26(1.04-1.53) \ddagger$ & $1.28(1.07-1.54) \ddagger$ & 0.40 \\
\hline \multicolumn{6}{|l|}{ Women } \\
\hline Follow-up, no. of person-years & 59696 & 31391 & 15938 & 29160 & \\
\hline No. of events & 175 & 222 & 93 & 324 & \\
\hline
\end{tabular}

Note: ref = reference group, event = coronary artery disease.

*The interaction term between waist circumference and triglyceride levels in predicting risk of coronary artery disease.

tAdjusted for age, total cholesterol level, high-density lipoprotein cholesterol level, systolic blood pressure, smoking status and presence of diabetes.

‡Significantly different $(p<0.05)$ from reference group.

$\S$ Significantly different $(p<0.05)$ from reference group, from group with normal waist circumference / elevated triglyceride levels, and from group with increased waist circumference / normal triglyceride levels. 
been proposed as a marker of the metabolic alterations associated with excess intra-abdominal adiposity, such as ectopic fat deposition (liver, skeletal and epicardial fat) and insulin resistance. Hypertriglyceridemia combined with an increased waistline could be a marker of lipid overflow resulting from a relative defect of adipose tissue to clear and store the excess triglycerides from overnutrition and lack of physical activity. ${ }^{1}$

We believe that the hypertriglyceridemic-waist phenotype should not replace the clinical criteria of the National Cholesterol Education Program for the clinical diagnosis of the metabolic syndrome. ${ }^{24}$ However, because high-density

\section{Men}

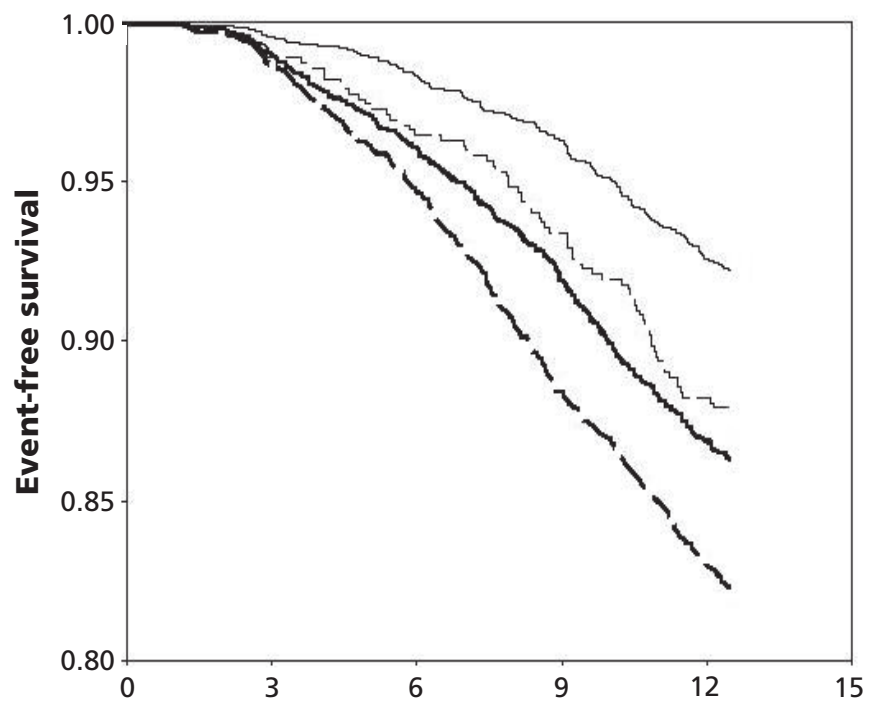

Women

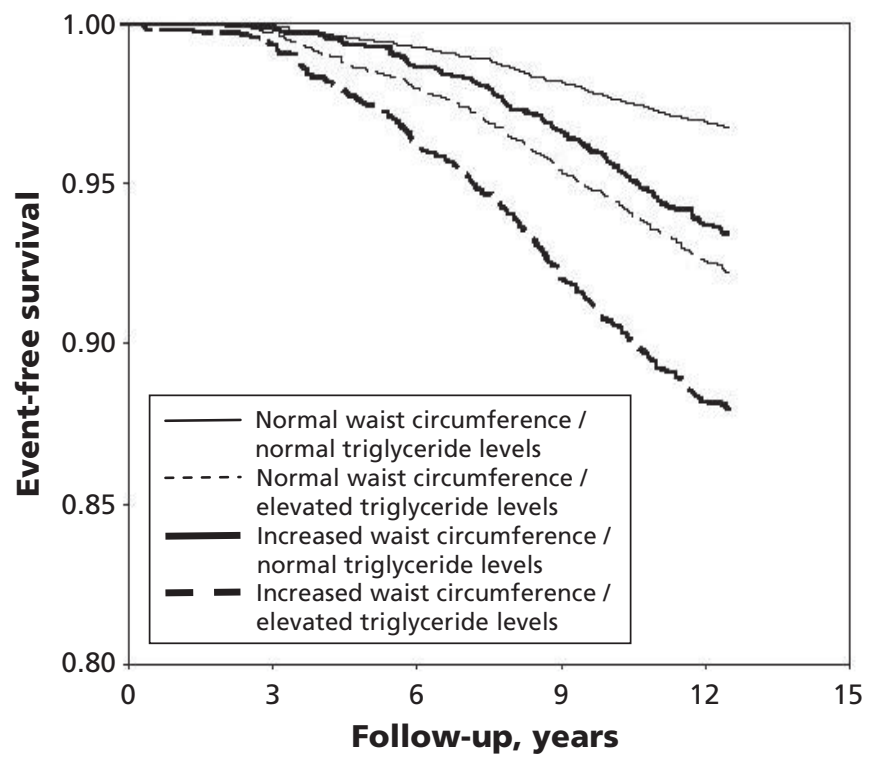

Figure 1: Kaplan-Meier curves showing the probability of remaining free of coronary artery disease among men and women stratified according to waist circumference and triglyceride levels. Normal waist circumference $=<90 \mathrm{~cm}$ in men and $<85 \mathrm{~cm}$ in women; normal triglyceride levels $=<2.0 \mathrm{mmol} / \mathrm{L}$ in men and $<1.5 \mathrm{mmol} / \mathrm{L}$ in women. lipoprotein cholesterol and systolic blood pressure are already included in the Framingham risk score, the addition of the hypertriglyceridemic-waist phenotype to the Framingham risk score would take into consideration traditional risk factors for coronary artery disease while providing additional information regarding the presence of excess intra-abdominal adiposity and associated metabolic abnormalities.

\section{Limitations}

Some aspects of our study merit further consideration. First, plasma triglyceride levels were determined in nonfasting sam-
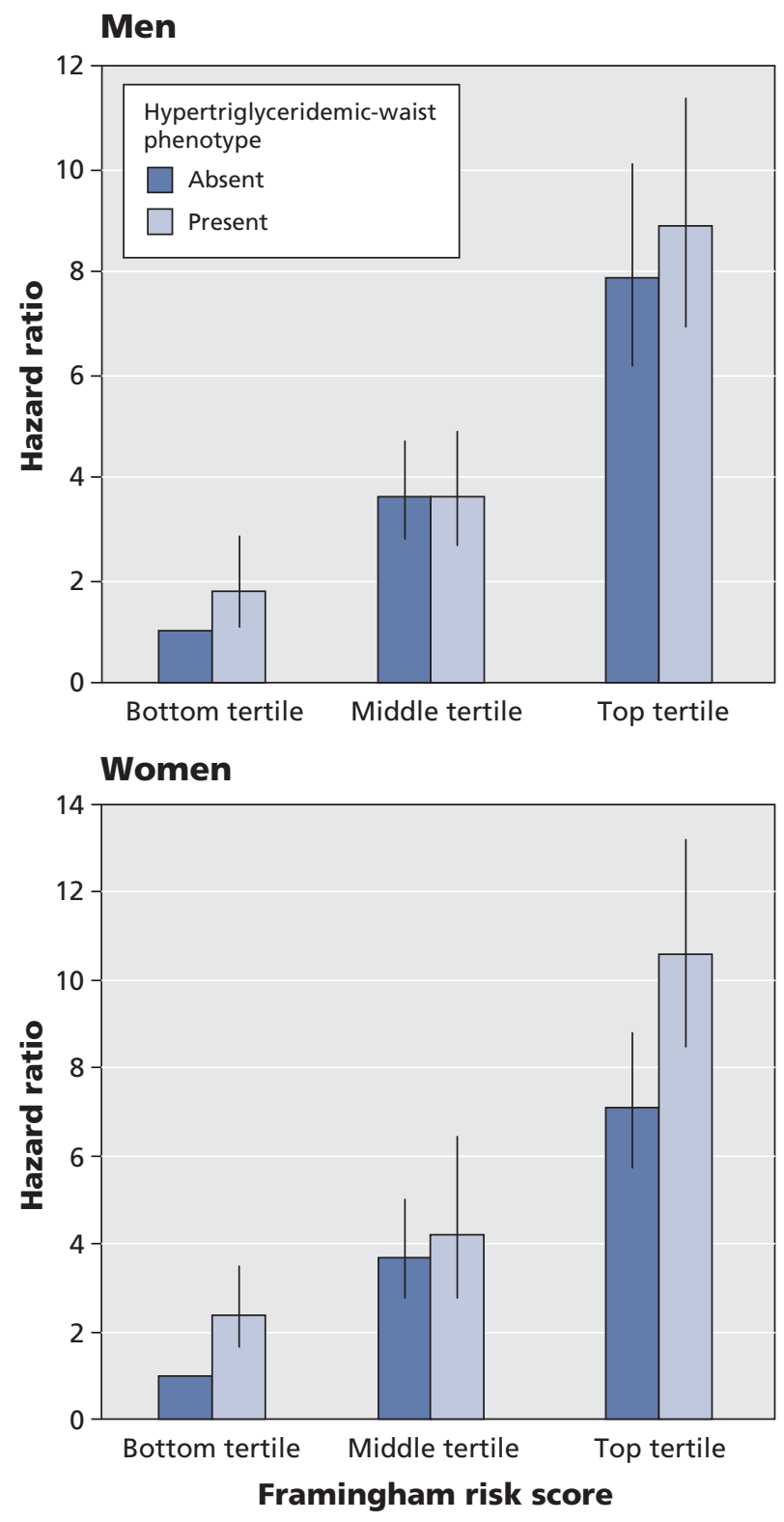

Figure 2: Hazard ratios for coronary artery disease among men and women according to Framingham risk score and presence of the hypertriglyceridemic-waist phenotype (waist circumference $\geq 90 \mathrm{~cm}$ and plasma triglyceride level $\geq 2.0 \mathrm{mmol} / \mathrm{L}$ in men ( $\geq 85 \mathrm{~cm}$ and $\geq 1.5 \mathrm{mmol} / \mathrm{L}$ in women). Error bars represent $95 \%$ confidence intervals. 
ples. This may have resulted in random misclassification of participants and reduced our ability to detect associations between the hypertriglyceridemic-waist phenotype and risk of coronary artery disease. However, recent studies have highlighted the usefulness of nonfasting triglyceride levels in the prediction of risk, possibly because metabolic abnormalities may be most pronounced in the postprandial state. ${ }^{25,26}$ Furthermore, in daily life, people are in the postprandial state for a good part of the day. Second, the presence of diabetes was self-reported, which might have led to an underestimation of any relationship. We believe that our large study sample may have attenuated the effect of these limitations. Third, our study sample comprised mainly white people, and therefore the results may not be translated to other populations. Additional studies from other populations and ethnic backgrounds are needed to better establish the role of the hypertriglyceridemic-waist phenotype as useful clinical screening tool in preventive cardiology. However, the INTERHEART study has shown that the health risks associated with obesity and body fat distribution are constant across various regions of the world in various ethnic groups. ${ }^{27}$

\section{Conclusion}

Our results show that the hypertriglyceridemic-waist phenotype was associated with an increased risk of coronary artery disease among men and women. This was the case even among participants without traditional risk factors for coronary artery disease. However, even though the phenotype is a marker of excess intra-abdominal adiposity, it cannot be used on its own to properly assess a patient's risk of coronary artery disease.

\section{This article has been peer reviewed.}

Competing interests: Benoit Arsenault is supported by a postdoctoral fellowship from the Fonds de la recherche en santé du Québec and the Fondation de l'Institut universitaire de cardiologie et de pneumologie de Québec. Jean-Pierre Després is Scientific Director of the International Chair on Cardiometabolic Risk, based at Université Laval. No competing interests declared by the other authors.

Contributors: Jean-Pierre Després, Nicholas Wareham, John Kastelein and Kay-Tee Khaw contributed to the study concept and design, the acquisition of data and the critical revision of the manuscript. Benoit Arsenault contributed to the acquisition of data and, with Isabelle Lemieux, Jean-Pierre Després and Matthijs Boekholdt, the analysis and interpretation of the data and the drafting of the manuscript. Benoit Arsenault and Matthijs Boekholdt were involved in the statistical analysis. Nicholas Wareham and Kay-Tee Khaw supervised the study. All of the authors approved the final version submitted for publication.

Funding: The EPIC-Norfolk study was supported by grants from the United Kingdom Medical Research Council and the United Kingdom Cancer Research as well as funding from the European Union, the Stroke Association, the British Heart Foundation, and Research Into Ageing. None of the sponsors had any role in the study design, the collection, analysis or interpretation of the data, the writing of the report or the decision to submit the manuscript for publication.

\section{REFERENCES}

1. Després JP, Lemieux I. Abdominal obesity and metabolic syndrome. Nature 2006; 444:881-7.

2. Lemieux S, Prud'homme D, Bouchard C, et al. Sex differences in the relation of visceral adipose tissue accumulation to total body fatness. Am J Clin Nutr 1993;58: 463-7.
3. Pischon T, Boeing H, Hoffmann K, et al. General and abdominal adiposity and risk of death in Europe. N Engl J Med 2008;359:2105-20.

4. Öhman MK, Shen Y, Obimba CI, et al. Visceral adipose tissue inflammation accelerates atherosclerosis in apolipoprotein E-deficient mice. Circulation 2008; 117:798-805.

5. Sam S, Haffner S, Davidson MH, et al. Relationship of abdominal visceral and subcutaneous adipose tissue with lipoprotein particle number and size in type 2 diabetes. Diabetes 2008;57:2022-7.

6. Sironi AM, Gastaldelli A, Mari A, et al. Visceral fat in hypertension: influence on insulin resistance and beta-cell function. Hypertension 2004;44:127-33.

7. Arsenault BJ, Lachance D, Lemieux I, et al. Visceral adipose tissue accumulation, cardiorespiratory fitness, and features of the metabolic syndrome. Arch Intern Med 2007; 167:1518-25

8. Pouliot MC, Després JP, Lemieux S, et al. Waist circumference and abdominal sagittal diameter: best simple anthropometric indexes of abdominal visceral adipose tissue accumulation and related cardiovascular risk in men and women. Am J Cardiol 1994;73:460-8.

9. Sam S, Haffner S, Davidson MH, et al. Hypertriglyceridemic waist phenotype predicts increased visceral fat in subjects with type 2 diabetes. Diabetes Care 2009; 32:1916-20.

10. Lemieux I, Pascot A, Couillard C, et al. Hypertriglyceridemic waist: A marker of the atherogenic metabolic triad (hyperinsulinemia; hyperapolipoprotein B; small, dense LDL) in men? Circulation 2000;102:179-84.

11. Lemieux I, Poirier P, Bergeron J, et al. Hypertriglyceridemic waist: a useful screening phenotype in preventive cardiology? Can J Cardiol 2007;23(Suppl B):23B-31B.

12. Bos G, Dekker JM, Heine RJ. Non-HDL cholesterol contributes to the "hypertriglyceridemic waist" as a cardiovascular risk factor: the Hoorn study. Diabetes Care 2004;27:283-4.

13. LaMonte MJ, Ainsworth BE, DuBose KD, et al. The hypertriglyceridemic waist phenotype among women. Atherosclerosis 2003;171:123-30.

14. Solati M, Ghanbarian A, Rahmani M, et al. Cardiovascular risk factors in males with hypertriglycemic waist (Tehran Lipid and Glucose Study). Int J Obes Relat Metab Disord 2004;28:706-9.

15. Day N, Oakes S, Luben R, et al. EPIC-Norfolk: study design and characteristics of the cohort. European Prospective Investigation of Cancer. Br J Cancer 1999;80 (Suppl 1):95-103.

16. Boekholdt SM, Peters RJ, Day NE, et al. Macrophage migration inhibitory factor and the risk of myocardial infarction or death due to coronary artery disease in adults without prior myocardial infarction or stroke: the EPIC-Norfolk Prospective Population study. Am J Med 2004;117:390-7.

17. Arsenault BJ, Lemieux I, Després JP, et al. Cholesterol levels in small LDL particles predict the risk of coronary heart disease in the EPIC-Norfolk prospective population study. Eur Heart J 2007;28:2770-7.

18. van der Steeg WA, Boekholdt SM, Stein EA, et al. Role of the apolipoprotein Bapolipoprotein A-I ratio in cardiovascular risk assessment: a case-control analysis in EPIC-Norfolk. Ann Intern Med 2007;146:640-8.

19. Lemieux I, Alméras N, Mauriège P, et al. Prevalence of "hypertriglyceridemic waist" in men who participated in the Québec Health Survey: association with atherogenic and diabetogenic metabolic risk factors. Can J Cardiol 2002;18:725-32.

20. Blackburn P, Lemieux I, Lamarche B, et al. Type 2 diabetes without the atherogenic metabolic triad does not predict angiographically assessed coronary artery disease in women. Diabetes Care 2008;31:170-2.

21. Czernichow S, Bruckert E, Bertrais S, et al. Hypertriglyceridemic waist and 7.5year prospective risk of cardiovascular disease in asymptomatic middle-aged men. Int J Obes (Lond) 2007;31:791-6.

22. Tanko LB, Bagger YZ, Qin G, et al. Enlarged waist combined with elevated triglycerides is a strong predictor of accelerated atherogenesis and related cardiovascular mortality in postmenopausal women. Circulation 2005;111:1883-90.

23. Lamarche $B$, Tchernof $A$, Mauriège $P$, et al. Fasting insulin and apolipoprotein $B$ levels and low-density lipoprotein particle size as risk factors for ischemic heart disease. JAMA 1998;279:1955-61.

24. Grundy SM, Cleeman JI, Daniels SR, et al. Diagnosis and management of the metabolic syndrome: an American Heart Association/National Heart, Lung, and Blood Institute Scientific Statement. Circulation 2005;112:2735-53.

25. Bansal S, Buring JE, Rifai N, et al. Fasting compared with nonfasting triglycerides and risk of cardiovascular events in women. JAMA 2007;298:309-16.

26. Nordestgaard BG, Benn M, Schnohr P, et al. Nonfasting triglycerides and risk of myocardial infarction, ischemic heart disease, and death in men and women. JAMA 2007;298:299-308.

27. Yusuf S, Hawken S, Ounpuu S, et al. Obesity and the risk of myocardial infarction in 27,000 participants from 52 countries: a case-control study. Lancet 2005;366: 1640-9.

Correspondence to: Dr. Jean-Pierre Després, Director of Research, Cardiology, Centre de recherche de l'Institut universitaire de cardiologie et de pneumologie de Québec, Pavilion Marguerite-D'Youville, 2725, chemin Sainte-Foy, Québec QC G1V 4G5;

jean-pierre.despres@criucpq.ulaval.ca 